\title{
OPEN
}

\section{4 \\ Advancing Our Approach to Global Justice for Children}

So far, we have outlined a concept of social justice for children in welfare states and criticized child poverty within them as unjust. We have argued that different agents are responsible for securing justice for these children and that the respective extent of their responsibility can be determined, at least approximately, using different criteria relating to the capacities of these actors and their role in the causation of child poverty, as well as their relation to the child and her living condition. The state and its institutions - education system, health care, social protection services and so on - are obviously the most important agents in this respect: as they possess metaresponsibility, they should enforce, if necessary, the responsibility of other agents. We have already discussed the international and global level briefly, acknowledging that it is of importance. We have argued, however, that we view the state and its institutions as the primary agent in the case of child poverty in modern welfare states they are still strong enough and have plenty of opportunities to shape their own institutions and societies. Still, child poverty in welfare states is more likely to be alleviated and eradicated if the international and global structures within which these states have to act and by which their opportunities and institutions are influenced also change. Nevertheless, welfare states can do much about child poverty even under the present unjust global structure. The situation is different for 'weaker' and developing countries, where child poverty is more widespread and severe. These countries have fewer opportunities, and it is very unlikely that child poverty in these regions can ever be eradicated without thinking about global justice; their problems are simply too closely intertwined with imbalances in the current global order.

It is clear that in poorer countries child poverty is a much more severe and widespread problem than in welfare states, where most poor children 
reach a level of well-being and well-becoming that is higher than that of most children worldwide. Yet one should never use these differences in the severity of absolute poverty, so to speak, to underestimate or downplay the severity of relative poverty; this is certainly not our intention in this chapter. Child poverty in welfare states is an injustice that weighs heavily and demands coordinated action. An examination of child poverty on the global scale, however, shows how it deprives even the most fundamental functionings and capabilities, leading to starvation, homelessness and death. These forms of deprivation constitute such blatant injustices that one can only wonder why it is still allowed to exist in a world that has reached such a high technological level.

UNICEF (2005) reported that in 2005 every second child in the world ( 1 billion) lived in poverty, that one in three children (640 million) in developing countries lived without adequate shelter, that one in five children (400 million) had no access to safe water and that one in seven children (270 million) had no access to health services. In 2011, close to 6.9 million children died before their fifth birthday, most of them due to a lack of access to nutrition and basic medical care (UNICEF 2012). These figures alone give a glimpse of how child poverty in poorer countries affects many dimensions of the physical, emotional, social and economic well-being and well-becoming of children and of how our world fails to deliver to these children what they are entitled to as a matter of justice. Hence, in this last chapter we wish to at least outline how we think our approach extends to these issues. We touch upon two aspects of particular importance: first, the task of identifying functionings and of setting thresholds that work as a benchmark for criticizing global child poverty; and second, the need to prioritize the attribution of responsibilities on a global scale.

In Chapter 1 we proposed criteria to help identify functionings children are entitled to as a matter of justice; we do not see why they should not be applicable to any context and to all children in this world. Built into these criteria, however, is the claim that the functionings and respective thresholds have to be interpreted according to the context in which a child lives and that the level of welfare in that country is of particular relevance. As we furthermore argued, thresholds of functionings as well as capabilities are best interpreted in terms of more specified functionings and capabilities. To come back to the earlier example, the adequate threshold for the general functioning of being educated can be the functioning of going to school for nine years or achieving an education that enables one to succeed in the labor market in that society. Thresholds are thus specifications of functionings, and it is possible to 
understand them in terms of a combination of different such specified functionings. The threshold of the functioning of being healthy can, for instance, be specified using three functionings: (a) living as many healthy life years as the average in that society, (b) receiving all vaccines medical evidence identifies as beneficial and (c) not being affected by more illnesses than others due to arbitrary features that cannot be traced back to voluntary choices as an adult or to innate features that cannot be altered by medical care without subjecting other persons to other injustices.

These three functionings refer to important aspects of being healthy, but whereas the first and the third directly address the status of being healthy, the second one is related to a preventive measure. This points to another important issue; namely, that the thresholds of functionings are often to be translated into functionings that affect the achievement of the respective functioning. The chosen threshold is, then, only an indirect specification. We have largely ignored such problems in the selection of concrete functionings and their thresholds; instead, we used a 'negative' approach to criticize the injustice of poverty by looking at what it does to the poor children compared with their nonpoor peers who live in the same country. We have not judged the effects of child poverty on education by using a particular threshold, but we examined how well children in poverty fare in the education system and what educational achievements they have compared with those of nonpoor school children. It can be criticized that this strategy to disclose injustices gives an inaccurate evaluation because it is possible that all children in a certain society are below the threshold for the functioning of education and that looking at the inequalities produced by child poverty does not give a clear picture of the problem. We are aware of that; unfortunately, we could not come up with a better answer than to say that for the context we are interested in - namely, modern welfare states - we assume that the majority of children are above the threshold and that looking at the inequality and disadvantage produced by poverty is what counts under such advanced circumstances. If one uses the threshold of going to school for six or nine years, nearly all children in modern welfare states reach this threshold, but as we made clear, there still exist injustices in education - a deprivation in the functioning to be educated - that are related to the socioeconomic position of the child. Furthermore, we did not tackle the question of whether comparative weighting of different functionings is reasonable and feasible, even necessary in some circumstances, but assumed that at least the four functionings examined in more detail are highly important - but are they equally important? 
For an expansion of our approach to cover global child poverty, these issues become even more problematic, since a sufficient answer for welfare states - to look at relative poverty and the disadvantages it produces - is surely not enough for developing countries. It could be argued that there is a much more urgent need to prioritize certain functionings in poorer countries - for example, health and nutrition - and to give them more weight than, say, education. Such a prioritization should not be understood as devaluing education. Poverty alleviation relies on improving education and also empowering poor people to become agents of justice; the role of education is crucial. Furthermore, as was argued in some detail, education can be seen as a fertile functioning, influencing many other aspects of a person's life and the lives of whole communities. Still, without having one's nutrition and basic health secured, education's value is usually marginal; thus there is good reason to secure first what is essential for survival and only then secure other functionings and capabilities. This reasoning has strong parallels to Henry Shue's arguments for a basic right to subsistence:

No one can fully, if at all, enjoy any right that is supposedly protected by society if he or she lacks the essentials for a reasonably healthy and active life. Deficiencies in the means of subsistence can be just as fatal, incapacitating, or painful as violations of physical security. The resulting damage or death can at least as decisively prevent the enjoyment of any right as can the effects of security violations. (Shue 1996, 24)

On the global level, using such absolute thresholds and specifying functionings that define them is necessary. This is a very tricky task, and poverty research is limited in what functionings it can use as well, since some are easier to measure and to survey than others. In some cases, the functionings used to measure poverty are the result of the data available. Sabina Alkire, a pioneer in the application of the capability approach in global poverty measurement, used the following six indicators to measure child poverty in Bangladesh (Alkire and Roche 2012):

(1) Nutrition. Children who are more than two standard deviations below the international reference population for stunting (height for age) or wasting (weight for height) or are underweight (weight for age). The standardization follows the algorithms provided by WHO's Child Growth Reference Study. 
(2) Water. Children who use water from an unapproved source, such as open wells or springs, or use surface water (time to reach the water source is not included because this information was not available for the Bangladesh Demographic and Health Survey 1997).

(3) Sanitation. Children who use an unapproved sanitation facility, such as a pit latrine without slab, open pit latrine, bucket toilet or a hanging toilet.

(4) Health. Children who have not been immunized by age two. Children are deprived if they do not receive at least eight of the nine vaccinations - bcg, dpt1, dpt2, dpt3, polio0, polio1, polio2, polio3, measles - or do not receive treatment for an illness involving an acute respiratory infection or diarrhea.

(5) Shelter. Children who live in a house with no flooring (i.e., a mud or dung floor) or inadequate roofing (overcrowding was not taken into account because the Bangladesh Demographic and Health Survey 1997 does not register the number of rooms used for sleeping).

(6) Information. Children with no access to a radio or television (i.e., broadcast media). This indicator applies only to children above age three.

Alkire herself is well aware that this selection reflects just a few dimensions of child poverty and that other important information is missing, but these pragmatic choices can be justified in empirical research -having some knowledge of a few functionings is always better than having none. For a concept of global justice, this is certainly not enough. Unfortunately, philosophers have seldom engaged with this task in such a way that they came up with functionings or capabilities that can really be measured. Nussbaum and others do write about the problem but do not provide us with many answers; it is unclear what the exact thresholds for capabilities on Nussbaum's list are, for being healthy, for example, or being able to use one's senses. Not long ago, Ingrid Robeyns called the capability approach radically underspecified (Robeyns 2006), a critique that is still valid. For children, developing beings that change significantly over a rather short period of time, these problems are even more compelling, and issues of poverty dynamics and evolving functionings and capabilities are more relevant. We do not aim to come up with a definite list of functionings and respective thresholds for these functionings in terms of specified measurable functionings either. What is important, though, is to tackle the problem of differences between contexts. The functionings described above and used by Alkire in the context of Bangladesh show that over 90 percent of children live in a 
house with no flooring or inadequate roofing, and the deprivation rates for nutrition, sanitation and information (access to broadcast media) are nearly 60 percent. These numbers speak for themselves and make the injustice of child poverty in Bangladesh and other developing countries clearly visible. But in regard to the nature and effects of child poverty in modern welfare states, these functionings provide us with barely any information at all. Still, there is poverty, and in the course of this book we have presented some of its moral implications. The fact that it cannot be measured using the functionings employed by Alkire in Bangladesh must not lead to the conclusion that the living conditions of the respective children are free from any problems.

Against this background, where should the thresholds be set? In which functionings should they be specified? There is a real danger in setting them either too low or too high. We see two different basic strategies for handling the questions, though with important variances. The first is to differentiate between countries and allow them to set their own thresholds, at least within reasonable limits. This approach is favored by Nussbaum and also by Sen, who has a far more pragmatic approach and leaves the selection of the relevant functionings and capabilities up to the respective nations or societies. Nussbaum has made her approach clear on numerous occasions:

Setting the threshold precisely is a matter for each nation, and, within certain limits, it is reasonable for nations to do this differently, in keeping with their history and traditions. (Nussbaum 2011, 41)

Indeed, part of the idea of the list is its multiple realizability: its members can be more concretely specified in accordance with local beliefs and circumstances. It is thus designed to leave room for a reasonable pluralism in specification. The threshold level of each of the central capabilities will need more precise determination, as citizens work toward a consensus for political purposes. This can be envisaged as taking place within each constitutional tradition, as it evolves through interpretation and deliberation. (Nussbaum 2000, 77)

There are at least two problems with this solution, of which Nussbaum and others are well aware; still, no one has come up with a sufficient answer so far. On the one hand, this differentiating approach produces results that seem to contradict the aim of a concept of justice; namely, to provide all children with sufficient functionings that they need for their well-being and well-becoming. Again, we use the example of education. Mario Biggeri and his colleagues researched child poverty in Afghanistan 
and used the percentage of primary-school-age children who are not enrolled in school to measure educational functioning (Biggeri, Trani and Mauro 2010). Interpreting this in normative terms in a concept of justice, we say that every child of primary school age is entitled to go to school. For a child in a welfare state like Germany or the United Kingdom, the threshold would be different due to the fact that nearly all children of that age are enrolled, making it much more reasonable to take completion of secondary education as a minimum standard. In the language of justice, each and every child in Germany is entitled, as a matter of justice, to finish secondary education because this is the basic threshold for the functioning of education. If one uses these two different thresholds, a puzzling and disturbing result is that a child who does not finish secondary education in Germany is evaluated as being wronged, while a child in Afghanistan in the same circumstances is not. This seems questionable, as these two children are different in no feature save the arbitrary one of birthplace. It would be unjust in itself, so it appears, to tolerate exactly the same deprivation for one child and criticize it for the other. Is the child living in Afghanistan not entitled to the same level of functioning in education as the child in Germany? Is she of unequal worth? Does she not have the same entitlement to wellbeing and well-becoming?

On the other hand, Nussbaum and others claim that for some functionings or capabilities, the threshold should be universal and in some even strictly egalitarian in the sense that every human is entitled to the same. An example for adults would be voting rights, which should be, according to Nussbaum, distributed equally; it would be unjust if a society decides to let only men vote or to let them vote for their household. An example for children would probably be the functioning to live free of exploitation (which is on the list of Biggeri); it seems reasonable and necessary to claim that each and every child, no matter in which society, is entitled to being equally free of exploitation, with all the relevant protections in place. The question then arises: what functionings and capabilities (of children) should be universal, and what thresholds should be used? Furthermore, it is not obvious who should be able give answers to these questions, and, again, the issue of power arises forcefully.

We believe that these difficulties give us enough reasons to dismiss this strategy and be in favor of the second one, which sets universal thresholds for all children wherever they live. This implies that the threshold children are entitled to reach in a specific functioning is the same in Austria, the USA, Bangladesh, India and South Africa. As we said 
in regard to some functionings, this is also claimed by proponents of the first strategy. We gave as examples voting rights and freedom from exploitations, where any differentiations between different members of society are clearly always wrong. But we go a step further and demand this feature for each and every functioning that matters for justice.

The crucial question, then, is how to set such universal thresholds, which should neither be too high, so that they cannot be reached by most countries, nor too low, so that many forms of injustices cannot be detected and criticized. We agree that solving this problem cannot be done by relying on philosophical reasoning alone and that empirical knowledge that goes beyond the scope of what we are able to provide here is needed. Nonetheless, we believe that a concept of global justice still has to come up with some answer that goes beyond simply handing over the problem to the social sciences or politicians.

Our solution is to claim that the threshold for each functioning (or capability, if it comes to older children) should be set at a level as high as it is already for the majority of children in welfare states. Let us explain this solution in more detail: the first assumption is that today's world is highly unjust and that children across the globe are hindered from developing and sustaining high levels in all important functionings. They die too young, they suffer from preventable diseases and they lack sufficient education as well as inclusion and political participation. We assume that this world could do a much better job and that its political, cultural, social and economic institutions could be designed and implemented in a much better way, reducing or even setting aside the inequalities between children - and between the countries they live in. We assume that all children in this world could reach the level of functioning reached by a majority of children in modern welfare states if the world just looked different. This is one main reason that we propose a universal threshold - it gives a clear picture of a world in which it is not enough that children in poorer countries are a little bit healthier than they are today, get a little more education and are a little less likely to be deprived of shelter, food and clean water. Doubtless, such a world would already constitute an improvement, but it is not one we should aspire to. The goal must be to improve the well-being and well-becoming of all children to a level that some children worldwide - and a majority of children in welfare states - enjoy today, simply because we can do it. We know that this account is connected to a very high level of sufficiency, one that is not even realized for all children in modern welfare states, but everything else seems too low. We do not strive for perfection with these thresholds either, and it should be clear enough that the level of 
well-being and well-becoming that the majority of children in welfare states enjoy (the best indication for a just threshold, in our view) are still far away from a maximum. In the first chapter, we have already dismissed a maximizing view in well-being and well-becoming for two reasons: first, it is too demanding on the side of those who are responsible for securing it for children, and second, it is highly unclear how such a maximum could be defined in the first place. Our threshold, instead, takes up a more realistic stance concerning what should be achieved; that it is already achieved for many children in many countries also counters the objection that such high thresholds are not feasible. If a few countries can do it, why should the whole world not be able to set up a much more inclusive welfare system, with social protection, education, health care and so on? Still, our approach leaves a lot of room for differentiation and different ways to realize justice for children. Here it is important not to mix thresholds of functionings with the conversion factors to achieve them. A threshold can, according to our account, take the form of enabling each and every child a comprehensive education that prepares them with the necessary skills and competencies to become active members of society, to make informed decisions and to be aware of the equal worth of all humans. This threshold has to be set in accordance with the levels of well-being and well-becoming currently achieved in modern welfare states and is, in this sense, not relative. It is oriented toward what is reasonably achievable and goes beyond typical capability theorists' rather relativist approaches. It is important to note, however, that we are dealing here with a threshold in terms of specified functionings - and so we argue for a universalist account (one adaptable through time and in general circumstances on a global level, though).

But the conversion factors to achieve this threshold can be very different. They can refer, for example, to a public school system that limits the role of private schools or to an active role by organizations and the early inclusion of children and adolescents in regional decisionmaking processes. Modern welfare states today show a wide range of such conversion factors, and it is often not clear which yields better results; it seems that there are always trade-offs to be considered and that a conversion factor that is highly beneficial to achieve one functioning has a slightly negative effect on a different functioning or that two conversion factors can come into conflict with each other. There is plenty of room for each society and state to design its own institutions. Such a universal threshold is also in line with what we did over the course of this book in regard to child poverty in welfare states and highly developed societies. Even within them, children in poverty fall short in 
comparison with their nonpoor peers and are contingently disadvantaged in many dimensions. These societies would be much more just if they enabled all children living within them to reach what is reached for the majority of children who are not poor.

The second question that seems crucial for a concept of global justice for children concerns attributing responsibilities. We have proposed a first systematization for children in welfare states, and the main difference to this in respect to global child poverty is probably the responsibility we can lay upon poor states and their institutions. Poorer countries, where child poverty is most severe and widespread, are much weaker than in the USA and European welfare states. These states have far less power and fewer opportunities to counteract child poverty in their countries, to secure justice for these children and allow them to achieve a sufficient level in each important functioning (Babb 2009; Williamson 2011). Most theorists of global justice acknowledge this inequality between states, especially the international political and economic order's role in producing and reproducing these inequalities, keeping poorer countries from developing and from building stronger social protection systems and achieving a higher level of welfare for their citizens.

Poor countries need trade for development. They do not get fair trading opportunities under the WTO regime; but one that failed to sign up would find its trading opportunities even more severely curtailed. Any poor country is forced to decide about whether to sign up to the WTO rules against the background of other rules that it cannot escape and that make it extremely costly not to sign up. One such rule is, for instance, that the people and firms of poor countries may not freely offer their products and services to people in rich countries. This rule enables the rich countries to exact a price for whatever limited access to their markets they are prepared to grant. Part of this price is that the intellectual property rights of rich-country corporations must be respected and enforced. Poor-country governments must help collect rents for those corporations, thereby driving up the cost of pharmaceuticals and foodstuffs for their own populations. Paying this price makes sense perhaps for poor countries, given their calamitous circumstances. But this calamity is due to a rule that the rich countries impose unilaterally, without any consent by the poor. (Pogge 2007, 43)

This leads us to conclude that the responsibilities of the agents of justice in regard to global child poverty should be weighted differently and that 
the agents on the international and global level have a much higher responsibility, while the states high up on the list when it comes to child poverty in welfare states move down. They are to a substantial extent the victims of injustices themselves and have only limited options to move their citizens, adults as well as children, out of poverty. Still, these states share some responsibility and are obliged to do what is in their power to secure justice for children living in their societies and to adapt their cultural, social, political and economic institutions in such a way that they provide the necessary conversion factors to let all children achieve a just threshold in each important functioning. Poor states are partially responsible for their own situation, and justice demands that they try to alter and enhance their capacities to change. This also applies to the people living in these states. We see here an analogy between poor states and poor parents: even if they have responsibilities of justice, as David Miller (2007) argues, for example, as soon as they are not able to fulfill them adequately, a different agent of justice, in this case richer and more powerful states, has to substitute. It would be unjust to hold poor states responsible for the costs of children's suffering, because they cannot be said to be responsible.

Furthermore, in the global context, some of our endorsed considerations on the sufficiency principle gain additional force (see Chapter 1). We urged an interpretation of the sufficiency principle combining a demand-side view with a supply-side view, claiming that those in privileged positions must give sufficient attention to inequalities in the distribution of functionings and capabilities. The meaning of 'sufficient attention' however, depends in large part on how urgent the needs of the 'demand side' are; that is, the people who are suffering. In addition, we presented a priority view consisting of three elements for tackling functionings. It asks how important a functioning is, how severe and widespread its deprivation, and what is needed to overcome the deprivation in this dimension. From these considerations it follows that alleviation of global child poverty is even more urgent than alleviation of child poverty in welfare states. Again, this diagnosis must not lead to the conclusion that relative child poverty is nothing to worry about. It is evident that global poverty (a) jeopardizes even children's most basic functionings (in fact it often leads to death), (b) exists to an extremely high degree and (c) can be alleviated considerably by relatively small changes to the global order. It therefore triggers strong claims of responsibilities on the supply side.

This brings us to a further group of agents that are assumed to have different kinds of responsibilities for global child poverty in respect to 
child poverty in welfare states: other persons in the global community of humans. We gave these agents of justice a rather low ranking in regard to child poverty in welfare states because most members have only limited capacities to change something and have only limited responsibility for the existence of child poverty. We took into account that the majority of agents in this global community are themselves poor or have a low status of well-being because they live in poorer countries. This is still true in the case of global child poverty, but nonetheless, many agents in the global community, people who live in welfare states, who are therefore much richer and have much more resources, can make a real difference. If a middle-class adult in a welfare state adopts a poor child from another welfare state, this child's situation will probably improve; this improvement, however, has to be weighed against possible harms; for example, when a child is removed from her biological parents and has to move to another country or the burden that is put upon the parentto-be. In the case of global child poverty, our skepticism regarding a responsibility that can be translated into a duty to adopt poor children without sufficient means seems less reasonable. Daniel Friedrich has recently defended such a duty to adopt (Friedrich 2013); as applied to the case of child poverty, it is true that moving a child likely to die or suffer severely over her whole life in her home country - perhaps even against her will and the will of her parents - to a middle-class parent or family in a welfare state would certainly improve her condition to such an extent that our counterarguments become less valid. This implies that there might indeed be such a duty to adopt, maybe with some caveats; for example, that this duty apply only to those who wish to have children in the first place or only as long as child poverty is as severe as it is now.

We note again that a concept of global justice for children should also make use of an ecological approach, such as the one proposed, and differentiate between different agents and their responsibilities. This implies giving the poor themselves and poor children, as they reach a certain level of competencies and maturity, a role in the alleviation of poverty and in the design and implementation of measures of justice (Deveaux 2013). Reasons for doing so are not limited to the fact that the poor have a right to be heard and included in decisions affecting them; there are also pragmatic reasons built on the knowledge that measures that take the poor seriously and are developed on the basis of real knowledge about them and their situation work better. Besides, taking the agency of the poor seriously is empowering (Drydyk 2013). This aspect of participation and empowerment of poor people is both relevant for 
global (child) poverty as it is for (child) poverty as it typically occurs in welfare states. In both contexts the poverty knowledge of poor people and their interest in overcoming their poverty and their children's give them, as we argued in Chapter 3, certain responsibilities, albeit limited ones, for action against child poverty. However, there is a relevant difference to be noted, too. The severe poverty of the global poor and their typically very limited scope of action leads to the conclusion that they have almost no responsibility toward poor children living in welfare states. On the contrary, it makes sense to assert that poor people in welfare states have certain responsibilities toward poor children in developing countries or failed states. They profit, albeit to a smaller degree than many of their fellow countrymen, from an unjust global order and often they contribute with their consumption, at least to some degree, to the upholding of structural injustices on a global level. It therefore makes sense to think about their relationship to poor children on a global level in terms of responsibilities and to call upon them to rethink their actions and behaviors in some aspects, as is generally done for members of affluent states. Naturally, the kinds and weights of responsibilities of agents within these societies differ; application of the grounds for attributing responsibilities that we identified in Chapter 3 will lead to the conclusion that generally the responsibilities of poor people in affluent societies toward the global poor are low compared with those of their rich and powerful fellow countrymen. However, they should not be completely ignored.

\subsection{Conclusions}

In this section, we have given some ideas how our critical theory of child poverty, which we developed first and foremost for modern welfare states in affluent societies, can be extended to the global level. We have defended the view that it is important to aim for relatively high thresholds in the most important functionings (and capabilities, if applicable) for children, independent from where they happen to be born. The basic commitment of the capability approach to show equal concern and respect for every human being points, in our interpretation, clearly toward this goal. It does not seem fair to apply different standards for well-being and well-becoming based on completely arbitrary features, and a reasonable point of reference seems to be provided by what has been already achieved for most children in welfare states. We are aware that this goal is, in practice, hard to achieve and often changes and that improvements have to be implemented pragmatically and in small 
steps. Still, a normative concept of justice should also open up horizons that are worth aspiring to. For this, it is not necessary to develop a transcendental theory of justice that tries to fully specify the concept in all details (Sen 2009). It is enough to work with the realistic and rather simple conception of justice we have developed in this book.

We acknowledge that what we have discussed here about a global concept of justice for children is just preliminary and is insufficient in many aspects. Capability theorists need to do more work to specify the functionings and capabilities children are entitled to and how the thresholds for each of them should be set. Our solution needs to be scrutinized in more detail to be proven a viable alternative to the most common strategy of using different thresholds in different nations, which we dismissed. Our examination of the attribution of responsibilities to different agents of justice is also just a first dip into a much wider issue. Nonetheless, we have argued that such an expansion of justice from the domestic to the global level is needed and that this demands aiming high and not being satisfied with making the lives of children in poverty just a little less harmful and deprived but making real progress. The fact that hundreds of millions of children are born into circumstances where even the most basic goods are missing and where it is just not possible for them to have a minimally decent life is surely not their fault and can never justify claiming less for them than what we claim for children who had the luck to be born in a welfare state. As a matter of justice, each and every child matters the same and has the same entitlements.

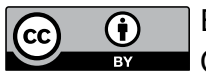

Except where otherwise noted, this work is licensed under a Creative Commons Attribution 3.0 Unported License. To view a copy of this license, visit http://creativecommons.org/licenses/by/3.0/ 